\title{
Spontaneous uterine rupture and surgical repair at 21 weeks gestation with progression to live birth: a case report
}

\author{
Lesley Hawkins ${ }^{1}$, Deborah Robertson ${ }^{1,2}$, Helena Frecker ${ }^{1,3}$, Howard Berger ${ }^{1,2}$ and Abheha Satkunaratnam ${ }^{1,2^{*}}$ (D)
}

\begin{abstract}
Background: Uterine rupture in the non-laboring uterus is a rare occurrence, which can lead to significant morbidity and mortality for the mother and fetus. Management of this presentation is complex at pre-viable gestations.

Case presentation: A 35 year old primigravid woman with multiple previous myomectomies presented with spontaneous complete thickness uterine rupture at 21 weeks gestation. A $10 \mathrm{~cm}$ myometrial defect and iatrogenic amniotomy were surgically corrected with fetal preservation. This led to pregnancy continuation to 32 weeks gestation when elective cesarean delivery resulted in excellent neonatal outcome.

Conclusions: Early surgical diagnosis, multidisciplinary team approach, iatrogenic amniotomy and continuous two-layer myometrial closure were factors that contributed to pregnancy prolongation in this large myometrial rupture.
\end{abstract}

Keywords: Uterine rupture, Spontaneous uterine rupture, Uterine wall defect, Second trimester

\section{Background}

Uterine rupture is defined as complete separation of the myometrium [1, 2]. It can occur in the laboring or nonlaboring uterus, the latter known as spontaneous uterine rupture. Spontaneous uterine rupture is a rare occurrence which can lead to maternal hemorrhage, placental abruption and extrusion of the amniotic sac and fetal parts through the uterine defect. This can result in significant consequences for both the mother and fetus, including blood transfusion, hysterectomy, urologic injury, neonatal respiratory distress, perinatal asphyxia and maternal or fetal death [3-5]. A history of uterine surgery has been identified as the most common risk factor for spontaneous uterine rupture in a small cohort of cases [6]. Less common causes include iatrogenic uterine perforation, invasive placenta, congenital anomalies, trauma and sacculation of the entrapped retroverted uterus [7].

Management of this rare pregnancy complication requires several considerations. Cesarean delivery with either

\footnotetext{
* Correspondence: abheha.md@gmail.com

'Department of Obstetrics and Gynaecology, University of Toronto, 123 Edward St, 12th Floor, Toronto, ON M5G1E2, Canada

2Department of Obstetrics and Gynaecology, St Michael's Hospital, 308-55

Queen St East, Toronto, ON M5C1R6, Canada

Full list of author information is available at the end of the article
}

uterine repair or hysterectomy may be appropriate at fetal viability. However, when the fetus is previable or extremely premature, management decisions are complex. Termination of the pregnancy with uterine repair or hysterectomy was the traditional approach [8]. In recent years, repair of uterine rupture in the second and early third trimesters has been reported, with successful delay of delivery [9-11]. We describe a rare case of spontaneous uterine rupture in the mid-second trimester and successful surgical repair including inadvertent iatrogenic amniotomy with continuation of pregnancy to 32 weeks gestation.

\section{Case presentation}

A 35-year old primigravid woman presented to hospital at 21 weeks 2 days gestation. She described a two-day history of periumbilical abdominal discomfort that suddenly became severe, waking her from sleep. There was no history of trauma. She was afebrile and had no other gastrointestinal symptoms. She had previously undergone four hysteroscopic myomectomies and one open myomectomy, during which 5 uterine incisions were made, including a fundal incision, and over 100 fibroids were resected. The indication for these surgeries was primary infertility, abnormal uterine bleeding and anemia. The interval between open 
myomectomy and conception was 26 months. The current pregnancy was spontaneously conceived and had been progressing normally.

At presentation, blood pressure was 99/54, heart rate 84 beats per minute, respiratory rate 20 , temperature 36 degrees Celsius (96.8 degrees Farenheit) and fetal heart rate 160 beats per minute. Abdominal examination revealed diffuse peritonitis and significant tenderness at the uterine fundus. Hemoglobin at presentation was $87 \mathrm{~g} / \mathrm{L}$ and white blood cell count was $10.89 \mathrm{E} 9 / \mathrm{L}$ (reference range $120-160 \mathrm{~g} / \mathrm{L}$ and 4.00 to $11.00 \mathrm{E} 9 / \mathrm{L}$, respectively). Ultrasound examination showed a live singleton fetus with normal amniotic fluid volume. The placental position was left posterofundal. Moderate volume hemoperitoneum was seen. Ovaries appeared normal bilaterally; the appendix was not visualized. Evaluation of the uterine wall demonstrated no focal uterine disruption or thinning, but was limited due to patient tenderness and bowel gas, therefore, a Magnetic Resonance Imaging (MRI) study was recommended. Urgent unenhanced abdominal MRI, completed that evening, $6 \mathrm{~h}$ following ultrasound examination, showed a sentinel clot at the left aspect of the uterine fundus, where the myometrium was markedly thinned, suspected to be the source of hemorrhage. During the diagnostic work-up, vital signs were stable and hemoglobin reached a stable nadir of $71 \mathrm{~g} / \mathrm{L}$.

Differential diagnosis included fibroid degeneration or torsion, placenta percreta, concealed placental abruption, uterine rupture and non-obstetrical causes. A patient care conference and complex consent process was undertaken to include several potential scenarios and outcomes. The patient was counselled extensively around possible complications of surgical repair, including prolongation of the pregnancy leading to severe prematurity, preterm rupture of membranes, and risks of unsuccessful repair, including hysterectomy and fetal loss. With a demonstration of an understanding of these risks, she consented to a diagnostic laparoscopy, uterine repair with possible laparotomy, possible hysterotomy and evacuation of the fetus and possible hysterectomy.

The following day, on the second day of admission, at 21 weeks 3 days gestation, the patient was taken to the operating room. The procedure was initiated laparoscopically via a left upper quadrant veress needle entry. A $10 \mathrm{~cm}$ complete thickness uterine fundus rupture was diagnosed (Fig. 1). Active bleeding was visualized from the edge of the rupture, and the chorioamniotic membranes were visibly bulging through the defect. Large hemoperitoneum (estimated $1000 \mathrm{~mL}$ ) was present. Given the extent and location of the defect, the size of the gravid uterus and visualization laparoscopically, we converted to midline laparotomy. Closure of the defect was then undertaken. Unintentional iatrogenic amniotomy occurred due to the suture needle shaft scratching the membranes. This resulted in

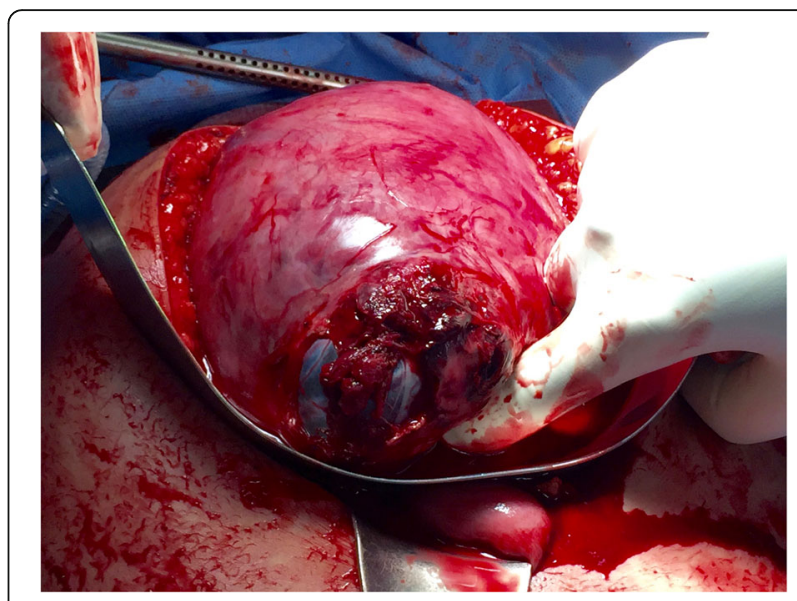

Fig. 1 At laparotomy, the $10 \mathrm{~cm}$ fundal complete uterine wall defect with protruding chorioamniotic membrane

two adjacent $2 \mathrm{~mm}$ defects in the amniotic sac and partial loss of amniotic fluid volume. Two large vascular clips were applied to each defect for repair. We introduced a 22 French foley catheter into the myometrial defect and inflated the balloon to displace the amniotic sac to facilitate uterine repair. With the membranes reduced, a two-layer uterine closure was successfully completed using full thickness continuous 0 polyglactin 910 (Vicryl) and imbricating 2-0 Polydioxanone (PDS, Ethicon, USA) sutures, respectively (Fig. 2). EVICEL and SURGICEL SnoW (Ethicon, USA) were applied to the area of repair to affect hemostasis. Intraoperatively, the patient required transfusion of 7 units packed erythrocytes, 2 units fresh frozen plasma and 1 unit cryoprecipitate; estimated total blood loss was $2500 \mathrm{~mL}$.

The patient's postoperative course was uncomplicated. Indomethacin was administered for tocolysis per the standard of care at our centre $(100 \mathrm{mg}$ per rectum then $25 \mathrm{mg}$ per os every $6 \mathrm{~h}$ for 4 doses). Postoperative intravenous cefazolin was administered for $24 \mathrm{~h}$. Fetal surveillance demonstrated amniotic fluid re-accumulation, appropriate growth parameters (estimated fetal weight 60-85\%ile) and normal fetal well-being. Amniotic fluid index (AFI) was $6.5 \mathrm{~cm}$ on postoperative day (POD) 3, $9 \mathrm{~cm}$ on POD4, $8.9 \mathrm{~cm}$ on POD5 and $12.5 \mathrm{~cm}$ on POD12. Myometrial thickness at the repair site was evaluated at several time points by ultrasound and ranged from 0.29 to $0.4 \mathrm{~cm}$. Ultrasound and MRI at 27 weeks gestation showed a $0.7 \mathrm{~cm}$ by $5 \mathrm{~cm}$ area of chorionamnion separation at the site of repair which remained stable throughout our patient's course (Fig. 3). The patient was transferred to a centre with Level 3 neonatal care at 24 weeks gestation, for continued inpatient observation, then transferred back to our Level 2.5 centre at 30 weeks gestation. A course of antenatal corticosteroids was administered at 25 weeks gestation. 


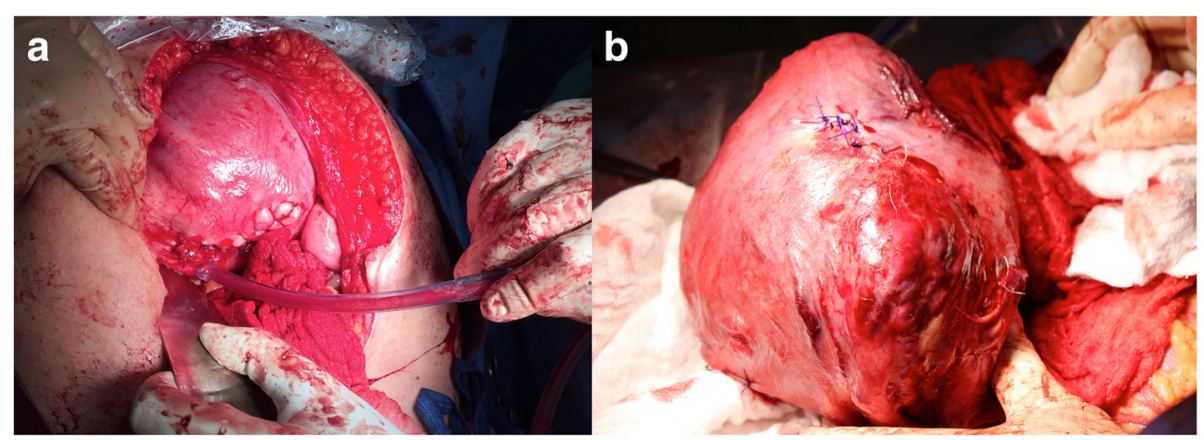

Fig. 2 a Two-layer closure of uterine defect following iatrogenic amniotomy and repair with surgical clips (not shown). b. Cesarean delivery: previous left fundal uterine rupture repair site intact, with remaining polydioxanone suture visible

Using a multidisciplinary approach, a second patient care conference was held involving Obstetrical, Gynecologic, Maternal Fetal Medicine, Pediatric, Anesthesia and Nursing teams to plan delivery. Consensus decision was achieved for planned cesarean delivery at 32 weeks 1 day gestation. This gestation was felt to be an optimal compromise between fetal maturity, and the maternal and fetal risks of sudden uterine rupture. A liveborn female, weighing $1884 \mathrm{~g}$ with Apgars of 8 and 9 at 1 and $5 \mathrm{~min}$, respectively, was transferred to the Neonatal Intensive Care Unit in good condition (umbilical artery pH 7.28). Intraoperatively, the previous uterine wall repair site was found to be intact at the fundus (Fig. 2B). Significant neovascularization was found on the serosal surface of the uterus. The myometrium had limited integrity, with several thin and weak areas. The fundal posterior placenta was markedly adherent; approximately $95 \%$ of it was felt to be removed. Estimated blood loss was $2000 \mathrm{~cm}^{3}$. Three

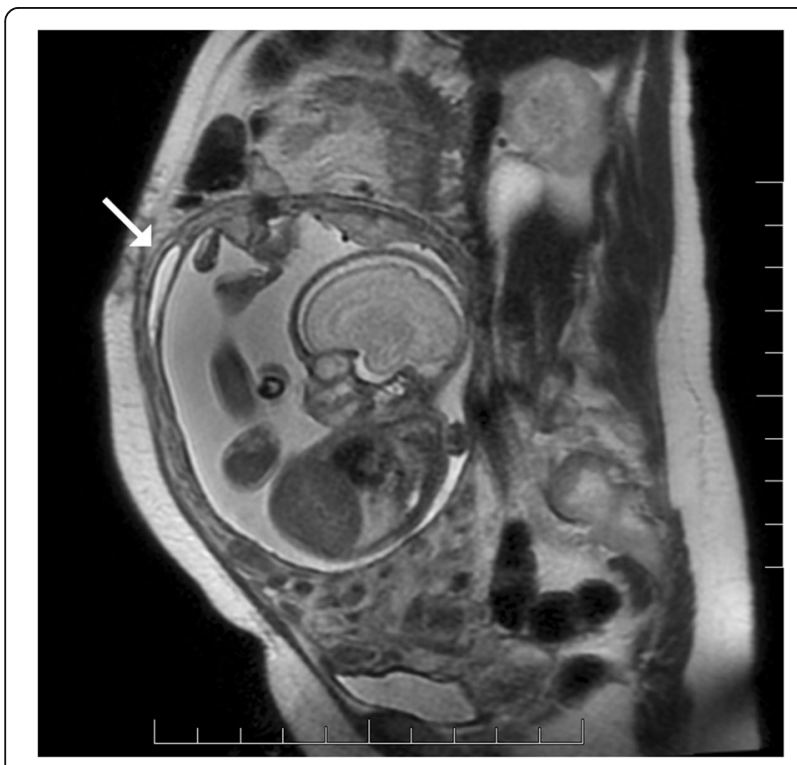

Fig. $3 \mathrm{MRI}$ showing $4 \mathrm{~mm}$ fundal uterine wall thickness and $0.7 \mathrm{~cm}$ by $5 \mathrm{~cm}$ amniotic fluid leak (arrow) surgical clips were retrieved intraoperatively, but the fourth was not easily palpated and given the clinical circumstances, left behind. In the perioperative period, the patient received 3 units packed erythrocytes.

Mother and infant were stable postpartum. The patient was discharged home on POD6. Her infant daughter received continuous positive airway pressure (CPAP) until day 2 of life. During her neonatal course, she underwent phototherapy for neonatal jaundice and was diagnosed with suspected cow's milk protein allergy. She met appropriate milestones and was discharged home on day 36 of life. Mother passed the last surgical clip spontaneously per vagina 10 weeks postpartum.

\section{Discussion and conclusions}

Rupture of the pregnant uterus at any time in gestation has a prevalence of $0.05 \%$ in population-based studies [4]. Spontaneous antenatal uterine rupture, however, has seldom been reported. A rare event, ten cases of spontaneous uterine rupture in the second trimester with successful repair have been described in a recent review by Surico et al. (2016). These cases presented at 13 to 26 weeks gestation and had a median pregnancy prolongation interval of 12 weeks. Identified risk factors in that series included previous cesarean delivery and previous uterine surgery, although some cases presented with no apparent risk factor [11].

Accurate pre-operative diagnosis was a challenge in this case. The most common presenting symptom of spontaneous rupture is sudden onset of severe abdominal pain, which happened to our patient. Vaginal bleeding, shock and fever have also been described [11]. Although ultrasound examination confirmed hemoperitoneum, its utility in diagnosing uterine rupture was limited. MRI has been shown to be useful in the work-up of acute abdomen in pregnancy in hemodynamically stable patients and has demonstrated superior accuracy in evaluation of uterine wall defects $[12,13]$.

A variety of repair techniques have been used in cases of spontaneous uterine rupture, including polyglactin 
910, PDS, Monocryl, chromic catgut sutures in interrupted and running fashion, GoreTex and Tachocomb patches and Vicryl and Surgicel mesh, which all resulted in successful pregnancy prolongation [11]. In our experience, the protruding amniotic sac provided significant tension to the edges of the ruptured myometrium, posing a technical challenge in safely and effectively opposing the edges. The iatrogenic amniotic sac defects were repaired with large vascular clips, providing an effective seal. In open fetal procedures such as in myelomeningocele, sacrococcygeal teratoma and fetal lung lesions, techniques used during creation of the hysterotomy include absorbable polyglycolic acid stapling devices and continuous locked running sutures which oppose the uterine wall edge to the chorioamniotic membranes, thus facilitating a water-tight hysterotomy closure at the end of the procedure [14-17]. In some cases of spontaneous uterine rupture, intraoperative needle amniocentesis has also been described [18-20]. In this case, unintentional amniotomy was found to be beneficial. However, planned amniotomy could be considered in future cases to facilitate closure. Amnioinfusion was not carried out intraoperatively, as we felt that myometrial healing of this compromised area would be better achieved under reduced tension. Serial postoperative ultrasounds showed complete reaccumulation of amniotic fluid several days postoperatively and maintenance of normal amniotic fluid index until delivery. Therefore, we have identified that iatrogenic amniotomy can be successfully repaired with surgical clips in sterile conditions; this is the first known description of its kind.

Several unique maternal and fetal concerns arise following emergency fetal surgery in addition to chorioamniotic separation and oligohydramnios. These include risk of repair dehiscence, postoperative infection, premature rupture of membranes and preterm labor [14]. Serial imaging was used to evaluate the uterine wall thickness post-repair (range 0.29 to $0.4 \mathrm{~cm}$ ). A cohort of normal pregnancies demonstrated mean fundal myometrial thickness in the second trimester of $5.9 \mathrm{~mm}$ [21], but the utility of scar monitoring in this unique circumstance is unknown and cannot be compared to surveillance protocols used to plan trial of labor after cesarean. Postoperative antibiotics were given for $24 \mathrm{~h}$. Alternative regimens include intrauterine antibiotics infused in warmed Lactated Ringer's solution, in addition to systemic antibiotics [14]. Our patient did not have any symptoms or signs of preterm labor throughout her course. Various protocols for tocolysis following fetal surgery have been described [14, 22, 23], and could be considered in uterine rupture cases.

A multidisciplinary team was formed to plan delivery including the patient's wishes. Factors that contributed to the decision-making process included fetal maturity, risk of developmental sequelae of severe prematurity, risk of secondary uterine rupture, risk of premature labor, and associated risk of fetal demise. Planned cesarean delivery was predicted to provide significantly superior maternal and neonatal outcomes as compared to expectant management with emergency delivery, due to the risk of secondary uterine rupture and its consequences. Confirmation of fetal pulmonary maturity has been reported in a similar case [10], but was not performed as it was decided that the results would not influence the timing of delivery. Risks of subsequent pregnancy and recurrent uterine rupture were discussed extensively; the patient declined the options of concurrent hysterectomy or tubal interruption. The same surgical team that was involved in the uterine rupture repair carried out the cesarean delivery in order to provide continuity of clinical care and surgical expertise.

In conclusion, a multidisciplinary team approach was crucial to navigating medical and ethical considerations. Insights into successful technical closure of uterine wall dehiscence included iatrogenic amniotomy and its repair and foley catheter balloon reduction of amniotic membranes allowing for superior myometrial reapproximation. Furthermore, these novel techniques resulted in successful continuation of pregnancy with excellent neonatal outcome after this rare presentation of previable spontaneous uterine rupture.

\section{Abbreviations \\ AFI: Amniotic fluid index; CPAP: Continuous positive airway pressure; \\ MRI: Magnetic resonance imaging; PDS: Polydioxanone; POD: Postoperative day \\ Funding \\ Funding was not used to complete this Case Report. \\ Availability of data and materials \\ All data generated or analysed during this study are included in this published article. \\ Authors' contributions \\ $\mathrm{LH}, \mathrm{DR}, \mathrm{HF}, \mathrm{HB}$ and $\mathrm{AS}$ have been involved in the conception, design, drafting and critical revision of this manuscript. $L H, D R, H F, H B$ and $A S$ have given final approval for publication of this manuscript.}

\section{Ethics approval and consent to participate}

According to our institutional policies, this Case Report required patient consent to participate which has been filed in the patient chart for our records. Research ethics committee approval was not required.

\section{Consent for publication}

We have obtained a signed consent from the patient described in this case and it has been filed in the patient chart for our records.

\section{Competing interests}

Dr. Howard Berger is a member of the editorial board in the capacity of Senior Editor of BMC Pregnancy and Childbirth. LH, DR, HF and AS declare that they have no competing interests.

\section{Publisher's Note}

Springer Nature remains neutral with regard to jurisdictional claims in published maps and institutional affiliations. 


\section{Author details}

'Department of Obstetrics and Gynaecology, University of Toronto, 123 Edward St, 12th Floor, Toronto, ON M5G1E2, Canada. ${ }^{2}$ Department of Obstetrics and Gynaecology, St Michael's Hospital, 308-55 Queen St East, Toronto, ON M5C1R6, Canada. ${ }^{3}$ Department of Obstetrics and Gynaecology, Michael Garron Hospital, Suite 311, 658 Danforth Avenue, M4J5B9 Toronto, Ontario, Canada

\section{Received: 15 May 2017 Accepted: 23 April 2018}

Published online: 04 May 2018

\section{References}

1. Scott JR. Avoiding labor problems during vaginal birth after cesarean delivery. Clin Obstet Gynecol. 1997;40:533-41.

2. Bucklin BA. Vaginal birth after cesarean delivery. Anesthesiology. 2003;99:1444-8.

3. Chauhan SP, Martin JN, Jr., Henrichs CE, Morrison JC, Magann EF. Maternal and perinatal complications with uterine rupture in 142,075 patients who attempted vaginal birth after cesarean delivery: a review of the literature. Am J Obstet Gynecol 2003;189:408-417.

4. Hofmeyr GJ, Say L, Gulmezoglu AM. WHO Systematic review of maternal mortality and morbidity: the prevalence of uterine rupture. BJOG : an international journal of obstetrics and gynaecology. 2005;112:1221-8.

5. Leung AS, Leung EK, Paul RH. Uterine rupture after previous cesarean delivery: maternal and fetal consequences. Am J Obstet Gynecol. 1993:169:945-50.

6. Vaknin Z, Maymon R, Mendlovic S, Barel O, Herman A, Sherman D. Clinical, sonographic, and epidemiologic features of second- and early thirdtrimester spontaneous antepartum uterine rupture: a cohort study. Prenat Diagn. 2008:28:478-84

7. Arbab F, Boulieu D, Bied V, Payan F, Lornage J, Guerin JF. Uterine rupture in first or second trimester of pregnancy after in-vitro fertilization and embryo transfer. Hum Reprod. 1996;11:1120-2.

8. Martin JN Jr, Brewer DW, Rush LV Jr, Martin RW, Hess LW, Morrison JC. Successful pregnancy outcome following mid-gestational uterine rupture and repair using gore-Tex soft tissue patch. Obstet Gynecol. 1990;75:518-21.

9. Sugawara T, Ogawa M, Tanaka T. Repair of uterine rupture during second trimester leading to successful pregnancy outcome: case study and Literature's review. AJP reports. 2014;4:9-12.

10. Matsunaga JS, Daly CB, Bochner CJ, Agnew CL. Repair of uterine dehiscence with continuation of pregnancy. Obstet Gynecol. 2004;104:1211-2.

11. Surico D, Amadori R, Vigone A, D'Agostino C, Dessole M, Surico N. Successful delivery after surgical repair of uterine rupture at 15 weeks of gestation: case report and brief review. Eur J Obstet Gynecol Reprod Biol. 2016;204:5-8.

12. Furey EA, Bailey AA, Pedrosa I. Magnetic resonance imaging of acute abdominal and pelvic pain in pregnancy. Top Magn Reson Imaging. 2014; 23:225-42.

13. Casciani $E$, De Vincentiis $C$, Mazzei MA, et al. Errors in imaging the pregnant patient with acute abdomen. Abdom Imaging. 2015;40:2112-26.

14. Adzick NS, Thom EA, Spong CY, et al. A randomized trial of prenatal versus postnatal repair of myelomeningocele. N Engl J Med. 2011;364:993-1004.

15. Bennett KA, Carroll MA, Shannon CN, et al. Reducing perinatal complications and preterm delivery for patients undergoing in utero closure of fetal myelomeningocele: further modifications to the multidisciplinary surgical technique. J Neurosurg Pediatr. 2014;14:108-14.

16. Adzick NS. Open fetal surgery for life-threatening fetal anomalies. Semin Fetal Neonatal Med. 2010;15:1-8.

17. Wenstrom KD, Carr SR. Fetal surgery: principles, indications, and evidence. Obstet Gynecol. 2014;124:817-35.

18. Fujii T, Kozuma S, Unno N, Kuwabara Y, Taketani Y. Successful pregnancy following antenatal closure of uterine wall defect. Int J Gynaecol Obstet. 2000;68:261-2.

19. Gorthi S, Simpson NA, Lodge V, Dunham RJ, Lane G. Management of asymptomatic mid-trimester lower segment scar dehiscence. Eur J Obstet Gynecol Reprod Biol. 2009;147(2):241.

20. Liao CY, Ding DC. Repair of uterine rupture in twin gestation after laparoscopic cornual resection. J Minim Invasive Gynecol. 2009:16:493-5.

21. Durnwald CP, Mercer BM. Myometrial thickness according to uterine site, gestational age and prior cesarean delivery. J Matern Fetal Neonatal Med. 2008:21:247-50.
22. Flake AW, Crombleholme TM, Johnson MP, Howell L, Adzick NS. Treatment of severe congenital diaphragmatic hernia by fetal tracheal occlusion: clinical experience with fifteen cases. Am J Obstet Gynecol. 2000;183:1059-66.

23. Hedrick HL, Flake AW, Crombleholme TM, et al. Sacrococcygeal teratoma: prenatal assessment, fetal intervention, and outcome. J Pediatr Surg. 2004;39:430-8

\section{Ready to submit your research? Choose BMC and benefit from:}

- fast, convenient online submission

- thorough peer review by experienced researchers in your field

- rapid publication on acceptance

- support for research data, including large and complex data types

- gold Open Access which fosters wider collaboration and increased citations

- maximum visibility for your research: over $100 \mathrm{M}$ website views per year

At BMC, research is always in progress.

Learn more biomedcentral.com/submissions 